\title{
COPE WITH SUCCESS IN SPORT
}

\section{Tatiana Iancheva, Milena Kuleva}

\author{
National Sports Academy "Vassil Levski”, Sofia
}

\begin{abstract}
A number of scientific studies in the field of sports psychology are aimed at revealing the reasons, factors and conditions, which lead to success. The other side of the problem - how we cope with success - remains underestimated. The effect of the subjective experience of success can lead to different behavior effects - from mobilization and psychic upsurge to self-reassurance, disorganization, and loss of activity. The consequences of success make the researchers examine their connection with different coping strategies.

The aim of the present study is to examine how success is defined, how its determinants and consequences are interpreted, and what their connection with the applied coping strategies is.

The research was done among 115 athletes, practicing different kinds of sport, divided into groups depending on their gender, age, and qualification.

We used: 1) Specially developed scale for surveying the attitude to success; 2) Coping Orientation s to Problems Experienced scale - COPE -1 (Carver, et al., 1989), adapted for Bulgarian conditions and optimized for sports practice (Georgiev at al., 2003).

Athletes define success mainly as confidence and assertiveness. Mobilization and belief in one's abilities is dominant. The most important factors for success are good preparation and input efforts. There are some negative consequences with some of the athletes - remissness, insufficient efforts, enhanced emotional reactions. The leading ones are cognitively engaged coping strategies. There are significant differences depending on age, gender, and qualification. The dependences between the researched indexes were given.

The obtained results and established regularities direct the attention to possibilities of control and regulation of the negative consequences in the process of preparation with appropriate purposeful, scientifically proven influences, part of which are the coping strategies.
\end{abstract}

Keywords: success, cope with success, sport, coping strategies. 


\section{INTRODUCTION}

Success, striving towards victory, towards achievement, towards improving sports result, towards physical perfection is an essential feature of sports activity.

"Agon" - the struggle to be the first, to get a prize, the aspiration to be the best, the competitiveness have been the essence of sport since ancient times.

Success is most often viewed as a positive result from a preliminarily set intention, and is connected with:

- The achievement of an objective, result, victory.

- Social recognition, approval, fame.

The subjective experiences of athletes during their sports-competitive activity are complex, various, and influenced by multiple factors. A number of scientific studies in the field of sports psychology are aimed at revealing the reasons, factors and conditions, whose complex influence leads to achieving or not achieving success in sport.

Another side of the problem, connected with the competitive realization of athletes, remains in the background - the specific influence of success on efficiency of sports behavior, on the level of activities, experiences, and consequences for the athletes during their further sportscompetitive activity. At the same time, our observations of the sports career of numerous elite competitors show that the way athletes perceive, interpret and cope with success or failure in competition determines to a great extent their future successful or not successful realization, as well as their overall sports and professional career.

The psychological analysis of the phenomenon "success in sport" reveals its complicated and multi-direction con- ditionality. A lot of questions, related to the problem, appear in this aspect and in the context of the connection between the preceding and future behavior of an athlete. A few aspects of interpretation are to be expected:

- Success as an outcome - result or "product" of a competition.

- Success as subjective experience.

- Success as a cognitive evaluation of the result of one's own activities and efforts.

- Experiencing success.

- Success as a motivator or disincentive of future behavior.

- Coping with success. Influence on the overall career.

The effect of the subjective experience of success can lead to different behavior effects - from mobilization and psychic upsurge to self-reassurance, disorganization, and loss of activity.

The experience could be of great emotional intensity and could have both positive and negative personal effect.

Sports life is intense, competitive, and elite.

The trend toward lowering age boundary in most sports leads to an early appearance and early publicity, and that is why the idea of self-dressing in power comes too soon.

Facing and solving the problems related to fame and publicity is an ordeal for the athlete. It requires the development of certain personal qualities and mechanisms, high level of development of self-control and self-regulation of one's behavior and actions. Success inspires, motivates, and brings satisfaction to athletes. But at the same time, it could become their most serious challenge. The problems, related to "fame vanity" concern, to the greatest 
extent, the field of sport and art, i.e., the areas with the biggest publicity and the widest social assessment. Sports fame could be dangerous because it might lead to certain distortions of the Self, which may create a number of problems both during sports-competitive career and after its completion.

As T. Strudwick (2016) points out, referring to young football players, they will very quickly receive attention and recognition on behalf of their peers, media, agents, scouts, and bigger clubs. "The decisive question is whether those young players can continue to work hard and focus on the right things" (T. Strudwick, 2016, p.381).

In a research done among coaches Millsetal (2012) reports that they often meet players whose lack of emotional maturity prevents them from developing as efficiently as their potential allows (Millsetal, 2012).

Some authors (Tracy and Robins, 2007a, 2007b) mention some potentially destructive or debilitative psychological processes caused by success, such as arrogance, narcissism, and hubris. The authors make a distinction between the authentic pride and hubristic pride. The authentic pride seems to be an adaptive emotion that is correlated with higher selfcontrol, and concentration of one's efforts towards achieving a goal, while hubristic pride often refers to impulsiveness and aggression, weaker ability to adapt, and becoming self-centered (Carverand and Johnson, 2011).

Other authors highlight the ability of world-class athletes to respond to success with an increased drive for more success, realistic expectations and willingness to move out of their comfort zone and seek fresh ideas from coaches and specialists (MacNamara, Button and Collins, 2010 a, 2010 b).

There is a specific connection and interrelation between the subjective experience of success and the characteristics of athletes' competitive behavior. It is based on the peculiarities of the personality, the mechanisms for personal regulation and self-regulation, the applied coping strategies, etc.

In most cases, the researchers deal with the problems referring to coping with failure and success seeking. The other side of the problem - how we cope with success - remains underestimated. Every athlete, coach, team that achieves success should adapt to it and cope with their personality and with the situation. As D. Haglind (2003) points out, the abilities of athletes to cope with their way of thinking and their behavior are especially important for the outcome of a certain competition, season, and overall sportscompetitive career.

Sports-psychological literature has persistently set the problem for coping with success - definition of success, how it is perceived and what the consequences of success are, how the coach helps his athletes cope with success, how the competitors react to success (Haglind, 2003; Conroy, Poszwardowski, and Henschen,2001). Regardless its big practical significance, the problem of coping with success in sport still does not receive enough attention on behalf of the specialists.

Discussing the problem of coping with success in sport, authors face a seemingly paradoxical problem for sport - fear of success, phobia of success. While fear of loss and fear of failure are regarded 
as one of the most common problems in sport and have been repeatedly surveyed and analyzed, fear of success can be accepted as natural to sport with difficulty. Research by Conroy, Poszwardowski and Henschen (2001) among 16 elite athletes and actors reveals that the consequences of success with some athletes are connected not only with achieving the desired result, improved image of oneself, and better relation with the others, but also with fear of success - the pressure of the greater expectations, the desire to be liked, the surprising "price" for achieving success.

The term "fear of success" was introduced in sport by Ogilvi (1968), Ogilvi and Tutko (1966). The authors define fear of success as a problem related to the result and outline some peculiarities of this phenomenon:

- Fear of social and emotional isolation;

- Difficult acceptance on behalf of former friends and alienation from the social group;

- Doubts about the value of their success;

„Guilt" about the things achieved;

- Fear about whether they will succeed again, whether they will reveal their true potential, whether they will repeat their previous achievement, etc.

It is the consequences of success that make researchers study their connection with different coping strategies.

Coping is defined by many scientists in the field of sports science as a complex, dynamic, and multidimensional process (Anshel, Jamisieson \& Raviv, 2001; Crocker \& Graham, 1995; Crocker \& Isaak, 1997; Eklund, Gould \& Jackson, 1993; Gould, Udry, Bridges \&
Beck, 1997). Coping aims at regulating emotions and changing behavior, so that we can deal with a particular situation. Coping with a certain situation requires change in behavior and/or in cognitions, so that we could manage the situation better. Lazarus and Folkman (1984) define it as "process of constantly changing cognitive and behavioral effort to manage specific external and/or internal demands or conflicts appraised as taxing or exceeding one's resources" (Lazarus \&Folkman, 1984, p.141). Coping is a response to the perception of threats which appear in sports environment. Most authors agree that coping consists of conscious psychological and psychical efforts to improve one's resourcefulness in dealing with stressful events or to reduce external demands (Anshel et al., 2001). But, of course, the implementation of certain coping strategies supposes awareness of the problem or knowing that the situation could raise problems.

Significantly important for the character of the experience of success or failure is the explanation which a person has about the reasons which have caused it. Whether one will attribute one's success or will account one's failure to internal or external reasons depends on the way one perceives oneself and determines the behavior in similar situation in the future. In a certain situation one may attribute one's actions to ability, effort, difficulty of the task, or luck (Weiner, 1986; Weiner, Frieze, Kukla, Reed, Rest, Rosenbaum, 1971). Thus, the mechanism of causative attributions plays role in the subjective interpretation of a particular result as success or failure and the reasons for it. It is of great importance for the sports activities and should be given special emphasis 
in the preparation of athletes.

The cognitive interpretation of success and its secondary evaluation determines to a great extent how the athlete would feel and react under similar circumstances in the future.

John Nicholls was the first to argue that success and failure are not concrete events but instead depend on an athlete's perception of whether he or she has reached his or her personal goals.

In this sense, there are a number of questions whose practical solution influences greatly the efficiency of competitive behavior and realization of an athlete: how success is defined and experienced, how the reasons for it are interpreted, what the consequences of success and the effects on further activities and competitive behavior are, how we cope with success.

\section{PURPOSE AND OBJECTIVES OF THE STUDY}

The aim of the present study is to examine how success is defined, how its determinants and consequences are interpreted, and what their connection with the applied coping strategies is.

\section{MATERIALS AND METHODS Participants}

The research was done among 115 athletes, practicing different kinds of sport, aged between 12 and 34 years. They were divided into four groups: 12-18 years old; 19-24 years old; 25-30 years old; over 30 years old. The average age of the subjects is 21.1 years old. There are 66 men and 49 women. The researched individuals were divided into two groups depending on their qualification: 1) medalists from international and national competitions - 46,2) engaged in sports without significant sports results -69 .

At the beginning of the research all participants were informed about the aim of the survey and their consent was obtained.

\section{Methods}

In order to fulfill the aim of the research we used:

1. Specially developed scale for surveying the attitude to success, which comprises three parts - definition and experience of success, interpretation of the reasons for success, behavior after success. Each of them includes two scales, as follows:

- Confidence, assertiveness.

- Prestige.

- Mobilization and belief in one's abilities.

- Emotional reactions, remissness.

- Preparation, efforts.

- Expectations.

The scale includes 33 items. The evaluation is given along a five point Likert Scale.

2. Coping Orientations to Problems Experienced scale - COPE -1 (Carver, et al., 1989). The test is adapted for Bulgarian conditions and it is optimized for sports practice (Georgiev at al., 2003). It includes 52 items, organized in 14 subscales. These fourteen strategies have been joined together through factor analysis into three generalized secondary factors: cognitive engagement, emotional engagement, cognitive and emotional disengagement.

\section{Statistical Analysis}

The software package used to analyze the final data from the research was SPSS 
21. The analyses made are the following: alternative analysis (to establish the relative shares of different responses in the questionnaires, as well as to assess the personal information - gender, age, sports experience, sports achievements), correlation analysis (the summation method $\chi^{2}$ with high level of statistical reliability $\alpha$ $\leq 0,01 ; \mathrm{P}_{\mathrm{t}} \geq 99 \%$ ), reliability analysis, regression analysis (to check the statistical significance of the model and the parameters of the functions), and comparative analysis (U-criteria of Mann Whitney and Criteria of Kruskal Wallis).

\section{RESULTS AND DISCUSSION}

The obtained results from the research of the attitude toward success are present- ed in table 1.

The data reveal that athletes define and experience success mainly as confidence and assertiveness $(\mathrm{M}=4.26$; SD $=.43$ ). The obtained results (Table 1) show that the predominant part of the subjects accept success as an incentive to prove themselves in future competitions, as confidence in their own qualities and abilities, assertiveness, a logical result from their own efforts and gaining necessary experience. We should point out that success is the least perceived as accidental.

Part of competitors define success as a source of prestige $(\mathrm{M}=3.49 ; \mathrm{SD}=.77)$. They believe they will prove themselves before others, will gain their trust and that

Table 1. Results from the variation analysis of the data

\begin{tabular}{|c|c|c|c|c|c|c|}
\hline Parameters & $\mathbf{N}$ & Min & $\operatorname{Max}$ & Mean & $\begin{array}{c}\text { Std. } \\
\text { Deviation }\end{array}$ & Variance \\
\hline Confidence, assertiveness & 115 & 2.33 & 5.00 & 4.26 & .59 & .301 \\
\hline Prestige & 115 & 1.40 & 5.00 & 3.49 & .77 & .593 \\
\hline Mobilization and belief in one's abilities & 115 & 2.60 & 5.00 & 4.16 & .49 & .239 \\
\hline Emotional reactions, remissness & 115 & 1.00 & 4.25 & 2.08 & .71 & .505 \\
\hline Preparation, efforts & 115 & 2.00 & 5.00 & 4.51 & .58 & .340 \\
\hline Expectations & 115 & 1.00 & 5.00 & 3.18 & .99 & .979 \\
\hline Cognitive engagement & 115 & 1.08 & 3.90 & 2.88 & .43 & .188 \\
\hline Emotional engagement & 115 & 1.00 & 3.83 & 2.48 & .52 & .272 \\
\hline Cognitive and emotional non engagement & 115 & 1.08 & 2.63 & 1.76 & .31 & .094 \\
\hline
\end{tabular}

will lead to a psychic upsurge (Table 1).

Special emphasis of our research is made on the consequences of success. The analysis of the results, connected with behavior after success, reveals that mobilization and belief in their abilities dominate with most of the athletes $(\mathrm{M}=$ 4.16 ; $\mathrm{SD}=.49$ ). Success leads to mobilization, to greater desire to train and to an increase in the belief in one's abilities, to expectation of series of wins. However, with part of the athletes, success leads to enhanced emotional reactions $(\mathrm{M}=2.08$; $\mathrm{SD}=.71)-$ overestimation of oneself or remissness and insufficient efforts.

The research into reasons for success is also interesting for sports practice and individual counseling, in so far as the secondary assessment (explanation of success) determines to a great extent how the competitor will act under similar circumstances in the future. The results show 
that the leading one is the scale "Preparation, efforts" $(\mathrm{M}=4.51 ; \mathrm{SD}=.58)$. The athletes regard good preparation, input of enough efforts and mobilization as the major determinants of success (Table 1). The scale "Expectations" shows lower values $(\mathrm{M}=3.18$; $\mathrm{SD}=.99)$. These results are of great practical significance. The results indicating the least significant factors fo $r$ success also have big practical application. They are: too strong desire for success, too high expectations on behalf of the others, and no expectations from the athlete. They reflect the attitude to view success as a temporary phenomenon, as something related to luck, which also leads to decrease in activity.

The comparative analysis of the results along the factor gender does not reveal significant differences among the scales.

There are significant differences along the factor qualification between the scales Mobilization and belief in one's abilities (Table2) and Preparation,

Table 2. Results from the comparative analysis along the factor qualification

\begin{tabular}{|c|c|c|c|c|c|c|c|c|c|}
\hline & 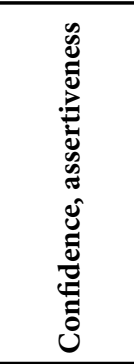 & 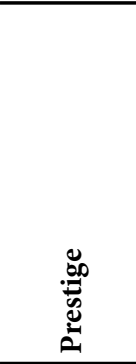 & 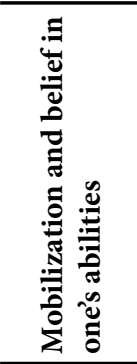 & 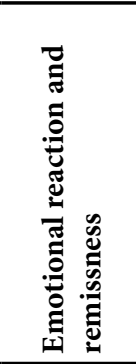 & 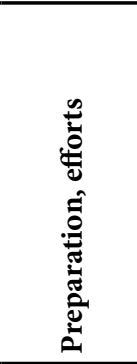 & 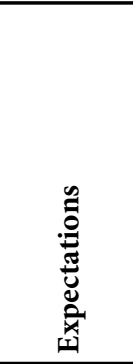 & 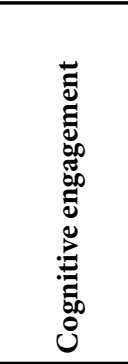 & 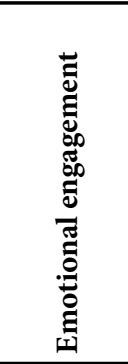 & 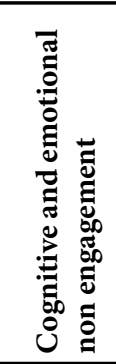 \\
\hline $\begin{array}{l}\text { Mann-Whit- } \\
\text { ney U }\end{array}$ & 1317.500 & 1356.500 & 1234.000 & 1542.000 & 1192.500 & 1441.500 & 1479.500 & 1393.000 & 1514.000 \\
\hline Wilcoxon W & 3732.500 & 3771.500 & 3649.000 & 2623.000 & 3607.500 & 2522.500 & 3894.500 & 3808.000 & 2595.000 \\
\hline $\mathrm{Z}$ & -1.547 & -1.322 & -2.033 & -.259 & -2.373 & -.842 & -.614 & -1.109 & -.417 \\
\hline $\begin{array}{l}\text { Asymp. Sig. } \\
\text { (2-tailed) }\end{array}$ & .122 & .186 & .042 & .796 & .018 & .400 & .539 & .267 & .676 \\
\hline
\end{tabular}

efforts. Elite athletes, to a greater extent, perceive success as an incentive to prove themselves, as confidence in their own qualities and abilities, as assertiveness and gaining necessary experience. They view success more as a consequence of good preparation, input efforts and mo- bilization.

The data reveals specific age dynamics (Fig. 1).

The analysis of the results, connected with coping strategies (Table 1), reveals that the leading one is the strategy cognitive engagement, which comprises active 


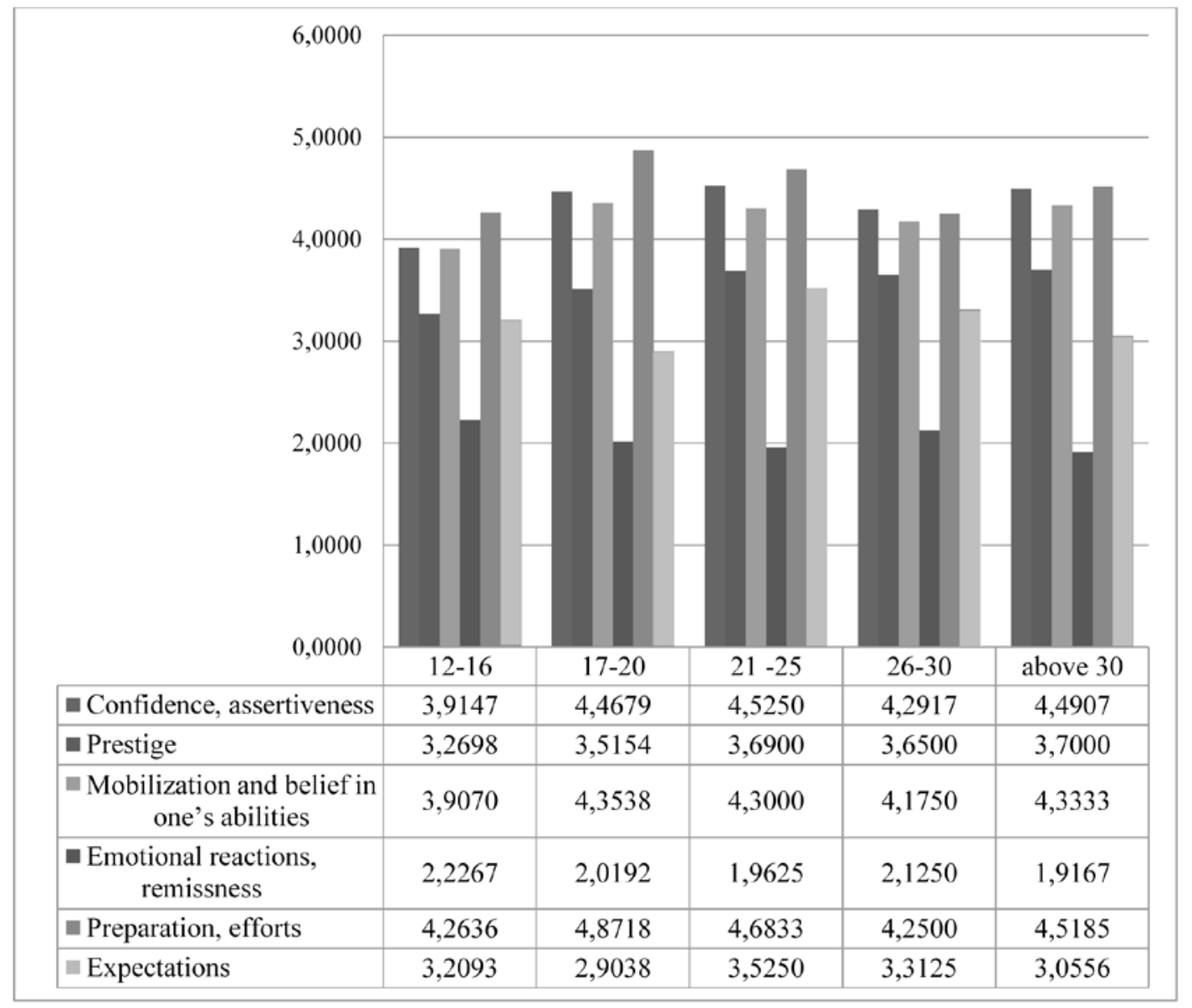

Figure 1. Mean values for the different age groups

There are significant differences Mobilization and belief in one's depending on age among the scales Con- abilities; Preparation, efforts (Table 3). fidence, assertiveness;

Table 3. Results from the comparative analysis along the factor gender

\begin{tabular}{|c|c|c|c|c|c|c|c|c|c|}
\hline & 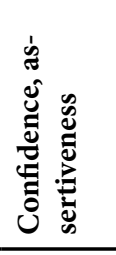 & 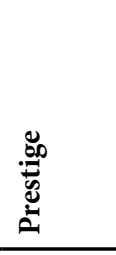 & 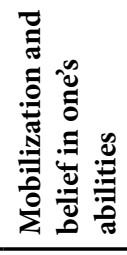 & 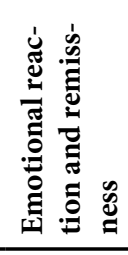 & 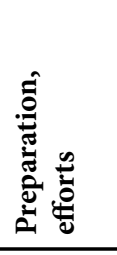 & 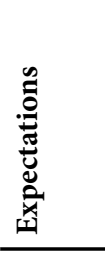 & 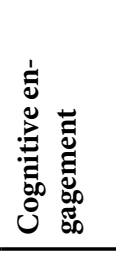 & 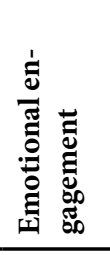 & 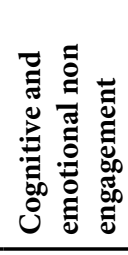 \\
\hline Chi-Square & 28.305 & 8.071 & 18.413 & 2.965 & 24.082 & 4.875 & 17.692 & 5.382 & .881 \\
\hline $\mathrm{df}$ & 4 & 4 & 4 & 4 & 4 & 4 & 4 & 4 & 4 \\
\hline Asymp. Sig. & .000 & .089 & .001 & .564 & .000 & .300 & .001 & .250 & .927 \\
\hline
\end{tabular}


coping, planning, suppressing competitive activities, positive rethinking, developing and restraining $(\mathrm{M}=2.88 ; \mathrm{SD}=.43)$. It is followed by the strategy emotional engagement $(\mathrm{M}=2.48 ; \mathrm{SD}=.52)$ - seeking advice and help, need of emotional response, compassion and mutual experience (Table 1).

The least preferred is the strategy cognitive and emotional non engagement $(\mathrm{M}$ $=1.76 ; \mathrm{SD}=.31)$, which comprises denial and non-acceptance, behavioral and psychic non engagement, alcohol and drug abuse, reconciliation with what has happened, turning to religion.

The results from the comparative analysis reveal significant gender differences regarding emotionally engaged strategies. Women tend to resort to this type of coping strategies more often than men.

There are expected differences between the cognitively engaged strategies with the age groups (Table 3 ).

There are no significant differences regarding the coping strategies used depending on qualification.

The correlation analysis of the data reveals some significant relations between the applied coping strategies and the different scales of success. There is a significant correlation between cognitively engaged strategies and the scales Preparation, efforts $(\mathrm{r}=0.452 ; \mathrm{p}=.000)$, Confidence, assertiveness $(r=0.480 ; p=.000)$, Mobilization and belief in one's abilities $(r=0.537 ; p=.000)$, and Prestige $(r=0.452 ; p=.002)$. This dependence is logical, in so far as cognitively engaged strategies are connected with active coping, planning, development leading to mobilization, a sense of control over the situation, and a rise in confidence. There is a significant dependence between emotionally engaged strategies and the scale Prestige $(r=0.257 ; p=.005)$; and a moderate one with Emotional reactions and remissness $(r=0.194 ; p=0.038)$. There is a significant correlation between the emotional reactions after success and the strategy Cognitive and emotional non engagement $(\mathrm{r}=0.345 ; \mathrm{p}=.000)$, and a moderate negative dependence with Preparation, efforts ( $\mathrm{r}$ $=-0.202 ; \mathrm{p}=.030$ ).

The question regarding the extent to which the components of success influence the coping strategies is also interesting. In order to measure the impact of these factors we used step by step regression analysis. The results reveal that Mobilization and belief in one's abilities $(\beta=$ $, 560 * * *)$ and Confidence, assertiveness $\left(\beta=, 238^{* *}\right)$ stimulate the use of cognitively engaged strategies. At the same time, Confidence, assertiveness $(\beta=-, 307 * *)$ influences emotionally engaged strategies (Table 4).

\section{CONCLUSIONS}

The obtained results allow a serious analysis and set a number of questions, related to the specificity of psychical load in

Table 4. Results from the regression analysis

\begin{tabular}{ccccc}
\hline \multirow{2}{*}{$\begin{array}{c}\text { Dependent } \\
\text { variables }\end{array}$} & \multicolumn{2}{c}{$\begin{array}{c}\text { Cognitive engagement coping } \\
\text { strategies }\end{array}$} & \multicolumn{2}{c}{$\begin{array}{c}\text { Emotional engagement coping } \\
\text { strategies }\end{array}$} \\
\cline { 2 - 5 } & $\mathrm{B}(\mathrm{t})$ & $\Delta \mathrm{R} 2$ & $\mathrm{~B}(\mathrm{t})$ & $\Delta \mathrm{R} 2$ \\
\hline $\begin{array}{c}\text { Mobilization and belief } \\
\text { in one's abilities } \\
\text { Confidence, } \\
\text { assertiveness }\end{array}$ & $.560(7.18)^{* * *}$ & 0.313 & \\
\hline
\end{tabular}


sport, the peculiarities of the pedagogical influences, as well as the very nature of the activities.

As a whole, the results from the research into the determinants of success and its influence on the efficiency of competitive behavior outline some important common regularities of great practical value.

The fact that most of the athletes perceive success as an incentive to prove themselves in future competitions, as a logical result from their efforts is something optimistic and leads to an increase in their own confidence. They develop a maximum attributive style, where success is a premise for mobilization of their efforts and an aspiration for improvement of their future performance.

Our results support the findings of other authors - personal expectations and confidence in one's own abilities for organizing and applying actions needed for achievement of a preliminarily set level of performance influence its efficiency.

On the other hand, the negative consequences of success with some of the athletes - remissness, insufficient efforts could lead not only to negative influence on the efficiency of sports-competitive ac-

\section{REFERENCES}

Anshel, M.H., Kim, K-W., Kim, B-H., Chang, K-J., Eom, H-J. (2001), A model for coping With stressful events in sport: Theory, application, and future directions, International Journal of Sport Psychology, 32(1), 43-75.

Carver, C., J. Weintraub, M. Scheier (1989), Assessing coping strategies: a theoretically based approach, Journal of Personality and Social Psychology, 56. tivity, but also, very often, to resignation from active sports activities. This, in turn, has an impact on the overall personal development and future way of life.

The excessive desire for success and too high expectations on behalf of the others, often prevalent in elite sport, are the least significant for success and reduce the efficiency of sports activities. This fact is also important for practice.

Big social expectations create additional premises for high psychic pressure in sport. Combined with high intrinsic motivation, they make the athlete face serious psychic ordeals. At the same time, they could be controlled and regulated, to a great extent, in the process of preparation, with appropriate purposeful, scientifically proven influences, part of which are the coping strategies.

There are a number of questions which remain unanswered:

To what extent does cope with success influence sports career and consequently professional and life career?

Which personal qualities are related to cope with success?

How can coaches help their players to cope with success?

Carver, C., and Johnson, S., (2011), Authentic and hubristic pride: Differential relations to aspects of goal regulation, affect, and self-control. Journal of Research in Personality 44: 698-703.

Conroy, D., Poszwardowski, A., Henschen, K. (2001), Evaluating criteria and consequences associated with failure and success for with athletes and performing artists.

Crocker, P.R.E., Graham, T.R. 
(1995), Coping by competitive athletes with performance stress: Gender Differences and relationships with affect, The Sport Psychologist, 9, 325-338.

Crocker, P.R.E., Isaak, K. (1997), Coping during competitions and training sessions: Are Youth swimmer consistent?, International Journal of Sport Psychology, 28, 355-369.

Eklund, R., Gould, D., Jackson, S. (1993), Psychological foundations of Olympic wrestling excellence: Reconciling individual differences and nomothetic characterization, Journal of Applied Sport Psychology, 5, 36-47.

Duda, J., \& Nicholls, J. (1993), The relationship of goal orientation to beliefs about success, perceived ability and satisfaction in sport, In: J. R. Nitsch \& R. Seiler (Eds.). Motivation, emotion, stress. (pp. 43-47), Proceedings of the VIII European congress of sport psychology Academia, Verland, Sankt Augusnin.

Georgiev, M., Domuschieva-Rogleva, G., Tosheva, I., (2003), Vtorichni factori i optimizirane na testa za izsledvane na predpochitanite strategii za spravyane sys stresa - COPE - 1. - V: Lichnost, Motivaciya, Sport, Knigi 1- 3. Prosport.S. (in Bulgarian).

Gould, D., Udry, E., Bridges, D., Beck, L. (1997), Coping with seasonending injuries, The Sport Psychologist, 11, 379-399.

Haglind, D. (2004), Coping with success and failure - Among Swedish and Portuguese track and field athletes and coaches, (European Master Dissertation in sport psychology), School of Social and Health Sciences, Halmstad University.

Iancheva, T., (2005), Zagubata i po- bedata $\mathrm{v}$ sustezatelnata realizaciya na sportista, Prilojna Psihologia i socialna praktika, S. 73-81. (In Bulgarian)

Lazarus, R.S., \&Folkman, S. (1984), Stress, appraisal and coping, Springer.

MacNamara, A., Button, A., and Collins, D. (2010a), The role of psychological characteristics in facilitating the pathway to elite performance, Part 1: Identifying mental skills and behaviors, Sport Psychologist 24:52-73.

MacNamara, A., Button, A., and Collins, D. (2010b), The role of psychological characteristics in facilitating the pathway to elite performance, Part 2: Examining environmental and stage-related differences in skills and behaviors, Sport Psychologist 24:74-96.

Mills, A., Butt, J., Maynard, I., and Harwood, C. (2012), Identifying factors perceived to influence the development of elite youth football academy players, Journal of Sports Sciences 30 (15): 1593-1604.

Ogilvi, B. (1968), The unconscious fear of success, Quest, 10, 35-39.

Ogilvi, B., Tutko, T. (1966), Problem athletes and how to handle them, Pelham, London

Strudwick, T. (2016). Soccer Science, Human Kinetics.

Tracy, J., and Robins, R. (2007a), The psychological structure of pride: a tale of two facets, Journal of Personality and Social Psychology 92:506-525.

Tracy, J., and Robins, R. (2007b), Emerging insights into the nature and function of pride, Current Directions in Psychological Science 16:147-150.

Weiner, B. (1986), An attributional theory of motivation and emotion, Springer-Verlag, New York 
Weiner, B., Frieze, I., Kukla, A., Reed, behavior, E. Jones, D. Kanouse, H. KelL., Rest, B., Rosenbaum, R. (1971), Per- ley, R. Nisbelt, S. Valins, B. Weiner, eds. ceiving the causes of success and failure. Morristown, NJ: General Learning Press. In Attribution: Perceiving the causes of

\section{Correspondence:}

Tatiana Iancheva National Sports Academy "Vassil Levski”, Sofia, Bulgaria E-mail: tiancheva@prosport-bg.net 